\title{
Mimicking the Chemistry of Natural Eumelanin Synthesis: The KE Sequence in Polypeptides and in Proteins Allows for a Specific Control of Nanosized Functional Polydopamine Formation
}

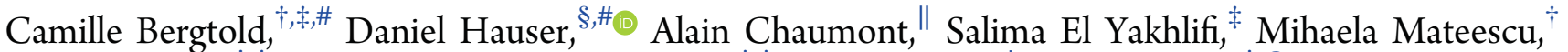
Florent Meyer, ${ }^{\dagger,}{ }^{\dagger}$ Marie-Hélène Metz-Boutigue, ${ }^{\dagger, \dagger}$ Benoît Frisch, ${ }^{\perp}$ Pierre Schaaf, ${ }^{\dagger, \bigcirc \odot ~ D r i s ~ I h i a w a k r i m, ~}{ }^{\nabla}$ Ovidiu Ersen, ${ }^{\nabla}$ Christophe A. Monnier, ${ }^{\S}$ Alke Petri-Fink, ${ }^{\S \odot}$ Barbara Rothen-Rutishauser, ${ }^{\S}$ and Vincent Ball $*,+, \uparrow$

\footnotetext{
${ }^{\dagger}$ Université de Strasbourg, Faculté de Chirurgie Dentaire, 8 rue Sainte Elisabeth, 67000 Strasbourg France

${ }^{*}$ Institut National de la Santé et de la Recherche Médicale, Unité Mixte de Recherche 1121, 11 rue Humann, 67085 Strasbourg Cedex, France

${ }^{\S}$ Adolphe Merkle Institute, University of Fribourg, 4 Chemin des Verdiers, CH-1700 Fribourg, Switzerland

"Faculté de Chimie, Chimie de la Matière Complexe, Centre National de la Recherche Scientifique, Unité Mixte de Recherche 7140, 4 rue Blaise Pascal, 67081, Strasbourg, France

${ }^{\perp}$ Université de Strasbourg, Faculté de Pharmacie, Laboratoire de Conception et application de molécules bioactives, 74 Route du Rhin, 67400 Illkirch-Graffenstaden, France

${ }^{\circ}$ Centre National de la Recherche Scientifique, Institut Charles Sadron, Unité Propre 22, 23 rue du Loess, 67034 Strasbourg, France

${ }^{\nabla}$ Centre National de la Recherche Scientifique, Institut de Physique et de Chimie des Matériaux, Unité Mixte de Recherche 7504,23 rue du Loess, 67034, Strasbourg, Cedex 2, France
}

\section{Supporting Information}

\begin{abstract}
The oxidation of dopamine and of other catecholamines leads to the formation of conformal films on the surface of all known materials and to the formation of a precipitate in solution. In some cases, it has been shown that the addition of additives in the dopamine solution, like certain surfactants or polymers, polyelectrolytes, and certain proteins, allows to get polydopamine nanoparticles of controlled size

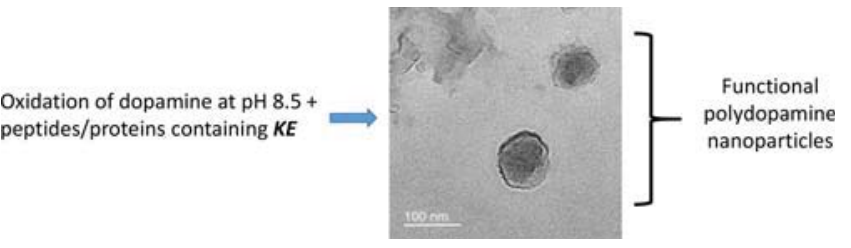
and the concomitant decrease, in an additive/dopamine dependent manner, in film formation on the surface of the reaction beaker. However, the mechanism behind this controlled oxidation and self-assembly of catecholamines is not known. In this article, it is shown that a specific diad of amino acids in proteins, namely KE, allows for specific control in the oxidation-selfassembly of dopamine to obtain polydopamine@protein core-shell nanoparticles which are biocompatible. The interactions between dopamine and the adjacent KE amino acids potentially responsible for the size control of polydopamine aggregates was investigated by molecular dynamics simulations. The obtained core-shell nanoparticles display the biological activity of the protein used to control the self-assembly of PDA. The photon to heat conversion ability of PDA is conserved in the PDA@ protein particles.
\end{abstract}

$\mathrm{E}$ umelanin in the skin is a hierarchical material made of grains a few hundred nanometers in diameter, and the melanins from the cuttlefish Sepia Officinalis also display a hierarchical structure. ${ }^{1,2}$ These black grains allow for an extremely efficient photoprotection of the skin. ${ }^{3-6}$ Melanins are also important for the pigmentation of the eyes and the hairs. Neuromelanins appear in the substantia nigra of the central nervous system where they play a central role in the protection of neurons against toxic species such as metal cations. $^{7-9}$ Natural eumelanin is synthesized by the oxidative self-association of L-3,4-dihydroxyphenylalanine (L-DOPA), a non-proteinogenic amino acid obtained through enzymatically catalyzed hydroxylation of L-tyrosine. ${ }^{10,11}$ The eumelanin

grains obtained in a biological environment are known to be surrounded by a layer of proteins. ${ }^{12}$ On the other hand in vitro synthesis of synthetic eumelanins from L-DOPA solutions yields huge, often polydisperse aggregates. ${ }^{13}$ Some attemps have been made to get monodisperse eumelanin-like particles without adjuvants by playing on the $\mathrm{pH}$ of the solution ${ }^{14}$ and by adding some cosolvents to water, such as ethanol. ${ }^{15,16}$ The synthesis in the presence of ethanol and ammonia allows to obtain spherical particles $260 \mathrm{~nm}$ in diameter. ${ }^{15,16}$ 
The properties and size of eumelanin (brown-black) or pheomelanin (yellow-reddish) particles also depend markedly on the nature of used monomers to be oxidized ${ }^{17}$ as well as on the oxidation pathway, either auto-oxidation in the presence of dissolved oxygen or enzymatically catalyzed oxidation. ${ }^{18}$ In the later case the formation of particles around $100 \mathrm{~nm}$ in final diameter seems to be a four step hierarchical self-assembly process. $^{19}$

The discovery that adjuvants such as poly(vinyl alcohol), ${ }^{20}$ surfactants, ${ }^{21}$ short tripeptides containing L-tyrosine, L-phenylanaline, and L-aspartic acid, ${ }^{22}$ human serum albumin (HSA), ${ }^{23}$ or the whole protein pool of egg white ${ }^{24}$ allow considerable reduction of the size of the eumelanin-like aggregates changed the perspectives on these eumelanin-like colloids which may find numerous applications in biomedical applications, materials science, ${ }^{25}$ and bioelectronics. ${ }^{6,26,27}$

An interesting approach to investigate synthetic analogues of eumelanin is to oxidize dopamine yielding a material conveniently referred as "polydopamine" (PDA). When charged surfactants are added to the dopamine solution during oxidation, the deposition of "polydopamine" (PDA) films on solid substrates, a universal coating method, ${ }^{28-30}$ was strongly inhibited whereas the size of the particles in solution progressively decreased from a few micrometers in hydrodynamic diameter to a few nanometers when the concentration of surfactants (sodium dodecyl sulfate, SDS, and cetyltrimethylammonium bromide, $\mathrm{CTAB}$ ) was increased above their critical micellar concentration. ${ }^{21}$ The size of the obtained PDA particles was found to be only slightly larger than the size of surfactant micelles, suggesting that the production of the eumelanin-like PDA material may be favored in the surfactant micelles. $^{21}$

In the case of human serum albumin (HSA), the obtained results suggest a different mechanism for the control of quite monodisperse PDA formation. ${ }^{23}$ HSA is a particular protein, being negatively charged at $\mathrm{pH}=8.5$, at which the PDA nanoparticles were synthesized. In the case of the whole protein extract from egg white, biomelanin nanoparticles from the oxidation of 5,6-dihydroxyindole as small as $15-65 \mathrm{~nm}$ in diameter could be obtained but without a detailed knowledge of the proteins implied in the size control from such a complex mixture. ${ }^{24}$ However, the use of tyrosine containing tripeptides, able to undergo self-assembly during tyrosinase mediated oxidation of L-tyrosine showed the importance of the amino acid sequence in the size and morphology of the eumelaninlike aggregates. ${ }^{22}$ Hence, it is useful to know if other proteins differing in their size and composition in amino acids (and hence in their isoelectric points) could play a similar role in controlling the size and in particular if specific sequences encoded information is required to ensure such a size/shape control of the obtained eumelanin-like particles. To solve such an enigma instead of proceeding in a trial and error manner, bioinspiration could be of high interest. Indeed, it is the composition of the mussel foot proteins, rich in L-DOPA and in L-lysine, which was at the origin of using dopamine to coat the surface of almost all known materials with so-called "polydopamine" films. ${ }^{31}$ In the present investigation, the inspiration not only came from the protein eumelanin composite particles in the skin or in Sepia Officinalis but also from the chromafin vesicles secreted by the adrenal medullary chromaffin cells. Chemical and biochemical analysis revealed that the chromaffin vesicles are simultaneously rich in catecholamines and in proteins such as chromogranin A ( CgA) and $\mathrm{B}(\mathrm{CgB})^{32}$ which mature upon controlled proteolysis to produce a large repertoire of regulatory peptides having a broad range of biological activities among them antimicrobial peptides. $^{33}$ Most often catecholamines are protected from oxidation in such vesicles and the interactions between CgA and catecholamines govern exocytosis. ${ }^{34}$ But occasionally in specific metabolic conditions, an oxidative stress for instance, the vesicles turn brownish implying oxidation of the present catecholamines. ${ }^{35}$ The possibility to control the oxidation of catecholamines leads to the assumption that among the pool of peptide sequences issued from CgA some of them should play a role in the control of oxidation processes and self-assembly of catecholamines into eumelanin-like nanoparticles. The identification of such short oligo-peptides (10-20 amino acids) should greatly help in understanding the role played by proteins in the controlled self-assembly of eumelanin-like materials in nanosized particles.

We will show herein that a specific diad of amino acid in such CgA derived peptides is sufficient to obtain controlled oxidation of dopamine in a PDA@peptide conjugate. The validity of this assumption was tested on a set of larger soluble proteins, namely bovine fibrinogen $(\mathrm{Fib}, \mathrm{pHi}=5.8, \mathrm{Mw}=$ $\left.340000 \mathrm{~g} \cdot \mathrm{mol}^{-1}\right)$, alkaline phosphatase from porcine mucosa (Alp, $\left.\mathrm{Mw}=140000 \mathrm{~g} \cdot \mathrm{mol}^{-1}\right)$, human hemoglobin $(\mathrm{Hb}, \mathrm{pHi}=$ $\left.6.95, \mathrm{Mw}=64000 \mathrm{~g} \cdot \mathrm{mol}^{-1}\right)$, hen egg white lysozyme $(\mathrm{HEL}$, $\left.\mathrm{pHi}=11.1, \mathrm{Mw}=14600 \mathrm{~g} \cdot \mathrm{mol}^{-1}\right)$, bovine milk alpha lactalbumin $\left(\alpha\right.$ Lact, $\left.\mathrm{pHi}=4.3, \mathrm{Mw}=14300 \mathrm{~g} \cdot \mathrm{mol}^{-1}\right)$, and a mixture of glucose oxidase $\left(\mathrm{GOX}, \mathrm{pH}_{\mathrm{i}}=4.2, \mathrm{Mw}=160000 \mathrm{~g}\right.$. $\mathrm{mol}^{-1}$ ) and horseradish peroxidase (POX, Mw $=44000 \mathrm{~g}$. $\mathrm{mol}^{-1}$ ). It could be shown that, among these proteins, those that allow inhibition of the deposition of PDA on the walls of the reaction beaker and simultaneous reduction of the size of PDA particles, in a protein/dopamine dependent ratio, all contain the same diad of amino acids, -KE- (K: lysine, E: glutamic acid) than the active peptides derived from CgA. The obtained PDA@protein nanoparticles, with sizes down to 20$30 \mathrm{~nm}$ in hydrodynamic diameter, are of the core-shell type, noncytotoxic for different cell types even at unusually high concentrations and can be used as catalysts of biochemical reaction after deposition in films using the layer-by-layer deposition method. ${ }^{36-38}$

\section{MATERIALS AND METHODS}

2.1. Chemicals. Dopamine hydrochloride (ref H8502), human serum albumin (ref A9511), alpha lactalbumin (ref L5385), bovine fibrinogen (ref; F8630), alkaline phosphatase from bovine intestinal mucosa (ref P7640), human hemoglobin (ref H7379), glucose oxidase from Aspergillus niger (GOX, ref G7141), and Horseradish peroxidase (POX, ref 8375) were purchased from Sigma-Aldrich and used without purification. Hen egg white lysozyme (ref 5933-D) was purchased from Euromedex (Schiltigheim, France). Poly(allylamine hydrochloride) (PAH, ref 283223, $56000 \mathrm{~g} \cdot \mathrm{mol}^{-1}$ as given by the furnisher) was dissolved at $1 \mathrm{mg} \cdot \mathrm{mL}^{-1}$ in 50 Tris(hydroxymethyl) aminomethane buffer (T-1503, Sigma-Aldrich). The $\mathrm{pH}$ of all solutions was measured with a HI221 $\mathrm{pH}$ meter (Hanna Instruments).

All aqueous solutions were made from Milli $\mathrm{Q}$ water $(\rho=18.2$ $\mathrm{M} \Omega . \mathrm{cm}$, RO system from Millipore).

2.2. Synthetic Peptides and Their Interactions with Dopamine in Oxidizing Conditions. Chromofungin (Chr) and Catestatin (Cat) are two chromogranin A ( $\mathrm{CgA}$ )-derived peptides corresponding respectively to the sequence of bovine CgA47-66 (RILSILRHQNLLKELQDLAL) and CgA344-364 (RSMRLSFRARGYGFRGPGLQL). They were provided from ProteoGenix (Schiltigheim, France). Five short peptides including $\mathrm{K}$ and $\mathrm{E}$ residues were 
provided by Pepmic (Suzhou, China). They correspond to the sequences KE (peptide 1), GKEG (peptide 2), GGKEGG (peptide 3), GGKGEGG (peptide 4), and GGKGGEGG (peptide 5). These sequences were validated by automated Edman sequencing and by Matrix Assisted Laser Desorption-Time Of Flight (MALDI-TOF) mass spectrometry at the Laboratoire de Spectrométrie de Masse BioOrganique, UMR7178 (CNRS-UDS) Strasbourg, France. The mass measurements were carried out on a Bruker BIFLEX MALDI-TOF spectrometer (Bruker Daltonics, USA) according to the procedure previously reported. ${ }^{39}$

2.3. Treatment of the Peptides with Dopamine and HPLCSEC Analysis. For each peptide we used a molar ratio dopamine/ peptide of 10 and the reaction was realized in $50 \mathrm{mM}$ Tris- $\mathrm{HCl} \mathrm{pH}$ 8.5 during $16 \mathrm{~h}$ at room temperature before analysis by HPLC-SEC (SEC holds for size exclusion chromatography).

After incubation, the mixture was analyzed by using a Dionex HPLC system (Ultimate 3000; Sunnyvale, CA USA) and a Tosoh Bioscience column (Interchim, Montluçon, France) TSK Gel G3000PWXL $(7.8 \mathrm{~mm} \times 300 \mathrm{~mm}$; particle size $7 \mu \mathrm{m})$. Absorbance was monitored at $214 \mathrm{~nm}$, and the eluent consisted in $50 \mathrm{mM}$ Tris$\mathrm{HCl} \mathrm{pH}$ 8.5. Material was eluted at a flow rate of $0.7 \mathrm{~mL} \cdot \mathrm{min}^{-1}$ by an isocratic program.

2.4. Antimicrobial Assays. Antibacterial activity of CgA-derived peptides Chr and Cat was tested by measuring the inhibition of bacterial growth. ${ }^{40}$ The Gram positive bacteria (Micrococcus luteus A270) were precultured aerobically at $37{ }^{\circ} \mathrm{C}$ in Mueller-Hinton Broth Medium (Becton-Dickinson Microbiology Company, Sparks, USA) at $\mathrm{pH}=7.4$. The bacterial strain was plated on the agar plates and cultivated for $24 \mathrm{~h}$ at $37^{\circ} \mathrm{C}$. After this incubation, one isolated colony was transferred to $10 \mathrm{~mL}$ of the Mueller-Hinton Broth medium and incubated for $22 \mathrm{~h}$ at $37^{\circ} \mathrm{C}$ to reach the stationary growth phase. Then the bacteria were suspended and diluted with Mueller-Hinton Broth medium to have a bacterial solution in the first phase of bacterial growth (A620 nm of 0.001; mid logarithmic phase). Finally, we have tested $10 \mu \mathrm{M}$ to $100 \mu \mathrm{M}$ of $\mathrm{Chr}(10 \mu \mathrm{L})$ and Cat $(10 \mu \mathrm{L})$ in $90 \mu \mathrm{L}$ of diluted bacterial solution by using 96-well plates (Sarstedt AG and Co., Nümbrecht, Germany). We used tetracycline (10 $\mu \mathrm{g} /$ $\mathrm{mL})$ and cefotaxime $(0.1 \mu \mathrm{g} / \mathrm{mL})$ as positive controls of growth inhibition. Microbial growth was assessed by the increase of the absorbance at $620 \mathrm{~nm}$ after $24 \mathrm{~h}$ of incubation at $37{ }^{\circ} \mathrm{C}$. The absorbance value control cultures growing without peptide corresponded to $0 \%$ of bacterial growth inhibition, while the culture with antibiotics was taken as $100 \%$. Each assay was performed three times.

2.5. Synthesis of Composite Protein-PDA Particles and Their Characterization. The used protein was dissolved at a given concentration in $50 \mathrm{mM}$ Tris buffer $(\mathrm{pH}=8.5)$ and after equilibration to ensure complete solubilization of the protein, this solution was slightly added to dopamine (H8502 from Sigma-Aldrich) to yield a catecholamine solution at $2 \mathrm{mg} \cdot \mathrm{mL}^{-1}(10.6 \mathrm{mM})$. This solution was gently shaken at $(25 \pm 2)^{\circ} \mathrm{C}$ during $24 \mathrm{~h}$ at $300 \mathrm{rpm}$ with a magnetic stirrer. This procedure may well induce some protein denaturation but is required to allow constant refreshing of dissolved oxygen which is mandatory to oxidize dopamine. The reaction time of $24 \mathrm{~h}$ was found sufficient to reach a plateau value in the absorbance of the solution at all wavelengths between 250 and $800 \mathrm{~nm} .{ }^{23}$ Small aliquots of the dopamine + protein mixture were regularly removed and diluted 20-fold with Tris buffer before measurement of the UV-vis spectra. Those spectra were acquired with a double beam $\mathrm{mc}^{2}$ spectrophotometer from Safas (Monaco) using Tris buffer in the reference cuvette. The obtained particles will be called PDA@protein particles. The eventually unbound protein and nonoxidized dopamine were removed from the reaction medium by dialyzing $25 \mathrm{~mL}$ of the suspension against $1 \mathrm{~L}$ of Tris buffer at $4{ }^{\circ} \mathrm{C}$ using dialysis membranes with a molecular weight cut off at $300 \mathrm{kDa}$ (Spectrapor) allowing for the diffusion of all the proteins excepted bovine fibrinogen $(340 \mathrm{kDa})$ out of the suspension in the dialysate. The dialysis was done at $4{ }^{\circ} \mathrm{C}$ in the dark and was repeated twice yielding a total dilution of the dialysate by a factor of 1600 . The dialysis step is important to remove eventually unbound proteins from the medium in order to ensure that any biological activity attributed to the proteins originated only from
PDA bound proteins. However, the PDA@fibrinogen suspensions were not dialyzed owing to the impossibility to get dialysis membranes with large enough pores.

The undialyzed and dialyzed PDA@protein containing solutions were characterized by dynamic light scattering using a Nano ZS device from Malvern working in the backscattering mode to allow the determination of the size distribution of the particles. The intensity autocorrelation function was analyzed with the Contin algorithm.

2.6. CryoTEM. Before analyses, a drop of the dialyzed PDA@ protein solution was deposited on an electron microscopy grid covered by a hydrophobic carbon membrane. The drop size was progressively reduced in order to obtain a thin film covering the whole membrane. The grid was subsequently plunged into ethane at liquid nitrogen temperature. By maintaining the specimen at this temperature, the grid was transferred on the cryo-holder and inserted in the column of the electron microscope. The specimens have been analyzed in a JEOL $2100 \mathrm{~F}$ (S)TEM microscope working at $200 \mathrm{kV}$ and equipped by a probe aberration corrector, an EELS (Gatan Tridiem) spectrometer, and an EDX ( $\mathrm{Si}-\mathrm{Li})$ detector. This setup allows to reach resolutions of 2 and $1.1 \AA$ under TEM and STEM modes, respectively. For limiting the irradiation damage, the images were acquired by using a low density of the electron beam.

2.7. Molecular Dynamics Simulations (MD). The dopamine + peptide systems were simulated by classical molecular dynamics "MD" using the AMBER.14 GPU software in which the potential energy U is empirically described by a sum of bond, angle, and dihedral deformation energies and a pairwise additive 1-6-12 (electrostatic + van der Waals) interaction between nonbonded atoms.

$$
\begin{aligned}
U= & \sum_{\text {bonds }} k_{b}\left(r-r_{0}\right)^{2}+\sum_{\text {angles }} k_{\theta}\left(\theta-\theta_{0}\right)^{2} \\
& +\sum_{\text {dihedrals }} \sum_{n} V_{n}(1+\cos (n \varphi-\gamma)) \\
& +\sum_{i<j}\left[\frac{q_{i} q_{j}}{R_{i j}}-2 \varepsilon_{i j}\left(\frac{R_{i j}^{*}}{R_{i j}}\right)^{6}+\varepsilon_{i j}\left(\frac{R_{i j}^{*}}{R_{i j}}\right)^{12}\right]
\end{aligned}
$$

Each simulated system is composed of one -GGXGG- peptide, one dopamine molecule, and about 3500 water molecules. Force field parameters for the peptide and for the dopamine molecule were taken from the AMBER ff14SB force field. ${ }^{41,42}$ Partial charges (Figure SI 2) used for the dopamine molecule were generated by performing RESP fitting ${ }^{43}$ of the electrostatically potential computed at the HF 6-31G* level using the GAUSSIAN09 software. The TIP3P model was used for water. ${ }^{44}$ Cross terms in van der Waals interactions were constructed using the Lorentz-Berthelot rules. The van der Waals and electrostatic interactions were scaled by a factor of 2 . The MD simulations were performed at $300 \mathrm{~K}$ starting with random velocities. System temperatures were set using a Langevin thermostat with a virtual collision frequency of $2 \mathrm{ps}^{-1}$. A time step of $2 \mathrm{fs}$ was used to integrate the equations of motion via the Verlet leapfrog algorithm. The trajectories were analyzed using the cpptraj software 43 , and snapshots along the trajectory were taken using the VMD software. $^{45,46}$

2.8. LBL Containing PDA@Alp and PDA@GOX+POX Films. Thirty milliliters of an aqueous solution of poly(allylamine hydrochloride) at a concentration of $1 \mathrm{mg} \cdot \mathrm{mL}^{-1}$ was prepared in a $50 \mathrm{mM}$ Tris buffer at $\mathrm{pH}=8.5$.

Identically, $30 \mathrm{~mL}$ of PDA-Alp or PDA@GOX+POX solution was obtained by adding $20 \mathrm{~mL}$ of Tris buffer at $\mathrm{pH} 8.5$ to $10 \mathrm{~mL}$ of dyalized nanoparticules, obtained as described previously.

A freshly cleaned Quartz glass slide (ethanol rinsing followed by plasma cleaning during 30 min using an PDC-32G-2 plasma cleaner from Harrick Plasma, USA) was immersed in the PAH solution for 5 $\mathrm{min}$ and then rinsed with buffer for $5 \mathrm{~min}$. Next, the glass slide was immersed into the PDA@Alp or PDA@GOX+POX containing nanoparticle solution for $5 \mathrm{~min}$ followed again with $5 \mathrm{~min}$ of contact with the Tris buffer. These deposition steps were repeated $n$ times to yield (PAH-PDA@Alp) or (PAH-PDA@GOC+POX) films. The 


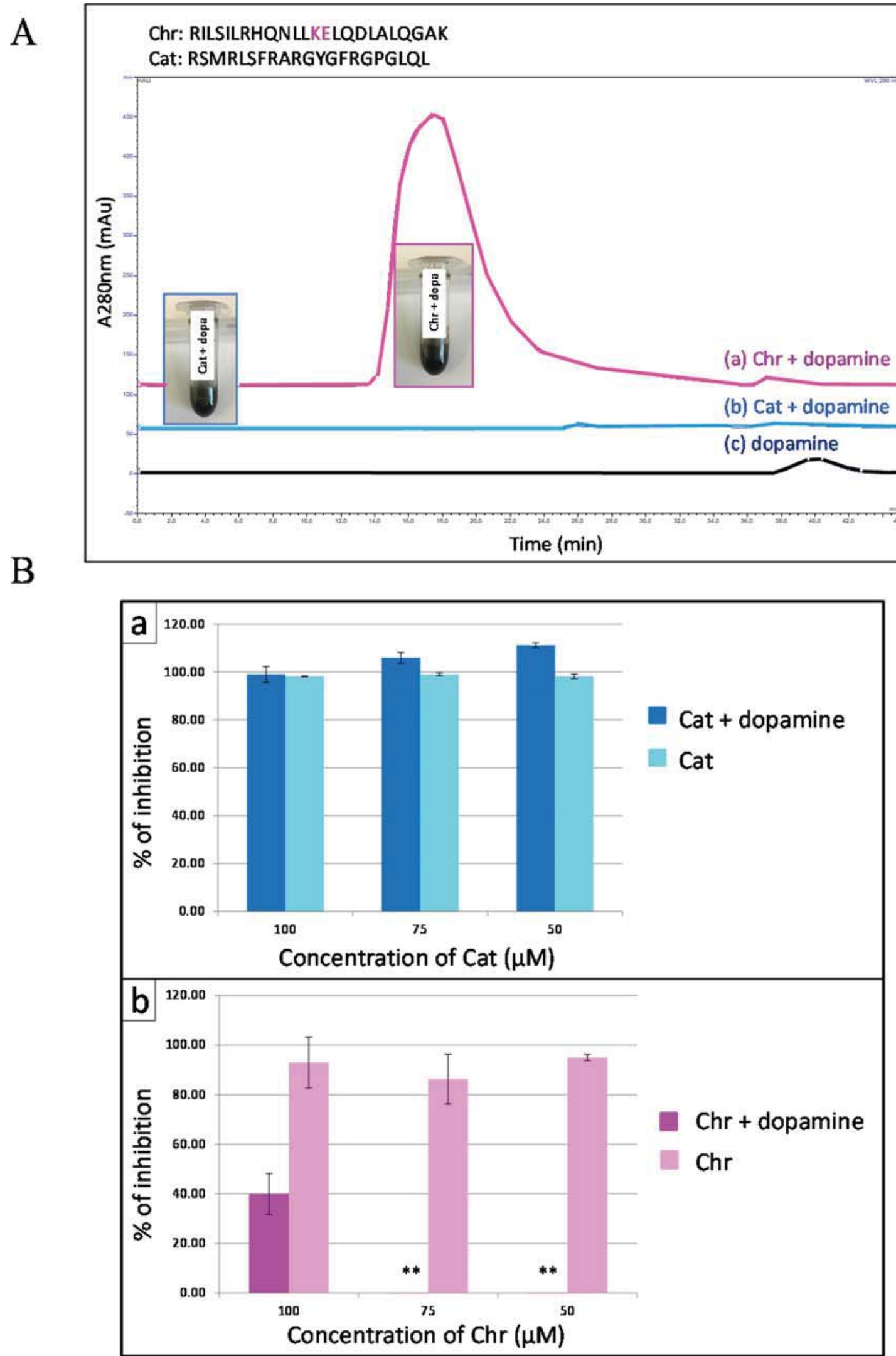

Figure 1. (A) Size exclusion chromatography (SEC) profiles of dopamine mixed with Tris buffer $(\mathrm{pH}=8.5)$ alone and in the presence of Chr and Cat. The inset digital pictures show that PDA formation occurs in all cases after $16 \mathrm{~h}$ in the presence of $\mathrm{O}_{2}$ from the air. The detection wavelength was set at $280 \mathrm{~nm}$. (B) Evolution of bacterial growth inhibition as a function of the peptide concentration (Cat in row a, Chr in row b) in the absence and in the presence of dopamine (the peptide/dopamine ratio was constant and equal to $1 / 10$ in all experiments). The ** symbol means that the inhibition is statistically not different from zero. 
optimal deposition time was determined by following the deposition process using a E1 quartz crystal microbalance device from QSense (Göteborg, Sweden). The adsorption substrate was a silica coated quartz crystal (QSense). The polyelectrolyte, nanoparticles, or buffer solutions were injected by means of a peristaltic pump at a constant flow rate of $250 \mu \mathrm{L} \cdot \mathrm{min}^{-1}$. The reduced frequency changes, $\Delta f_{\nu} / \nu$, as well as the dissipation changes, $\Delta D_{\nu}$, at the third $(\nu=3)$, fifth $(\nu=5)$, and seventh $(\nu=7)$ overtone were followed as a function of time. When the reduced frequency changes were smaller than $0.5 \mathrm{~Hz}$ per minute, the adsorption process of each polyelectrolyte was considered to be finished.

The deposition of PDA or PDA@protein conjugates in alternation with PAH on the surface of freshly cleaned silicon slides (Siltronix France) was also followed by means of ellipsometry (PZ 2000, Horiba, Longjumeau-France) operating at a constant angle of incidence of $70^{\circ}$ and at $\lambda=632.8 \mathrm{~nm}$. The silicon slides were regularly removed from the reaction medium, rinsed with distilled water, and dried under a stream of nitrogen. The film thickness was determined on five independently chosen locations on $1 \mathrm{~cm}^{2}$ coated silicon slides. The ellipsometric angles were transformed in film thickness assuming a model of a uniform PDA film with a refractive index of $1.73 \pm 0.02 \mathrm{i}$ at $\lambda=632.8 \mathrm{~nm}^{47}$

The morphology of the (PAH@PDA@Alp) 8 and (PAH@PDA@ $\mathrm{GOX}+\mathrm{POX})_{8}$ films was investigated directly on the quartz crystals used for the QCM-D experiments. The coated face of the quartz crystal was rinsed with distilled water (to avoid for the deposition of salt crystals issued from the buffer solution) and gently dried under a stream of nitrogen before gluing the crystal on the $\mathrm{J}$ piezoelectric scanner of the used Atomic Force Microscope (Nanoscope III, Veeco). The surface was imaged in the dry state in contact mode at a frequency of $1 \mathrm{~Hz}$ applying the lowest possible deflection set point and using an MLCT-C cantilever with a nominal spring constant of $0.1 \mathrm{~N} \cdot \mathrm{m}^{-1}$.

2.9. Enzymatic Assays on the PDA@Alp and PDA@GOX +POX Containing Films. The activity of the (PAH@PDA@Alp) films was measured by immersing the quartz slide covered with the film in $4 \mathrm{~mL}$ of paranitrophenyl phosphate (PNP) solution at $3 \times$ $10^{-5} \mathrm{~mol} \mathrm{~L}^{-1}$ in the presence of $50 \mathrm{~mL}$ Tris buffer at $\mathrm{pH}=8.5$. The absorbance increase due to the formation of paranitrophenol was measured at $\lambda=405 \mathrm{~nm}$ with respect to a reference cuvette containing PNP at the same concentration (in order to compensate for the spontaneous hydrolysis of PNP).

Coupled enzymatic reactions used in this study consist in conversion of glucose and $\mathrm{O}_{2}$ by GOX in D-glucono- $\partial$ lactone and $\mathrm{H}_{2} \mathrm{O}_{2}$. Then, $\mathrm{POX}$, using, the $\mathrm{H}_{2} \mathrm{O}_{2}$ produced from the hydrolysis of glucose, oxidizes the fluorescent peroxidase substrate, gaïacol, in a purple colored product.

To that aim, the glass slides covered with (PAH-PDA@GOX $+\mathrm{POX})_{8}$ films were introduced in the plastic cuvette containing $4 \mathrm{~mL}$ of $1 \mathrm{mg} \cdot \mathrm{mL}^{-1}$ glucose in $50 \mathrm{mM}$ Tris buffer $(\mathrm{pH} 8.5)$ and $80 \mu$ Lof peroxidase substrate. The reaction was followed by monitoring the absorbance at $\lambda=570 \mathrm{~nm}$, during $1 \mathrm{~h}$, at room temperature.

At the end of the experiment, the quartz lamella was intensively washed with buffer and kept at $4{ }^{\circ} \mathrm{C}$ before the next measurement of enzymatic activity (after 7 days or 14 days of storage).

2.10. Evaluation of the Cytotoxicity of Protein-PDA Particles. J774A.1 mouse monocyte/macrophages and MRC-5 human fibroblasts were cultured in RPMI (Gibco) supplemented with 10\% FBS (Gibco), 1\% penicillin/streptomycin (Gibco), and 1\% L-glutamine (Gibco) or modified eagle medium (Gibco) with added 10\% FBS (Gibco), 1\% penicillin/streptomycin (Gibco), 1\% Lglutamine (Gibco), and $1 \%$ nonessential amino-acids (Gibco), respectively. The cell lines were incubated at $37{ }^{\circ} \mathrm{C}$ and $5 \% \mathrm{CO}_{2}$.

To assess possible cytotoxicity, either $5 \times 10^{4}$ fibroblasts or macrophages were seeded in each well of an 8-well slide (BD Falcon 8 Chamber Polystyrene Vessel Tissue Culture Treated Glass Slide). To take the substantially slower proliferation of fibroblasts into account, the incubation was prolonged to $96 \mathrm{~h}$, whereas the fast-growing macrophages were exposed after $24 \mathrm{~h}$. The supernatant was then replaced with $480 \mu \mathrm{L}$ media containing different concentrations of
PDA@HSA nanoparticles and the slides were incubated again for 24 h. Subsequently, the supernatant was collected and stored for the quantification of lactate dehydrogenase (LDH) activity, and $2.2 \mathrm{mg}$. $\mathrm{mL}^{-1}$ resazurin solution was added instead. After an additional $3 \mathrm{~h}$ of incubation, the amount of resorufin, a metabolic product of resazurin, was measured by its specific absorption.

2.11. Illumination of the PDA@HSA Suspensions with UVLight and Measurement of Temperature Changes. To measure the PDA@HSA nanoparticles' ability of heat generation by light irradiation, a common property of eumelanin particles, ${ }^{16,48}$ the following arrangement was used: different amounts of PDA@HSA nanoparticles in water were added to a cuvette. The cuvette was placed in between an UV detector (Hönle UV technologies) and an UV laser (Hönle UV technologies, bluepoint 4), equipped with a filter allowing only light with a $\lambda$ of $320-390 \mathrm{~nm}$ to pass. After set up mounting, the surrounding box was closed due to safety reasons and the laser was activated for $100 \mathrm{~s}$, irradiating the sample with $0.9 \mathrm{~W}$. $\mathrm{cm}^{-2}$. Meanwhile, an IR camera (Optris PI) facing the cuvette recorded the temperature increase and the UV detector monitored the absorption $\left(\right.$ absorption $_{\text {Sample }}=0.9 \mathrm{~W} / \mathrm{cm}^{2}-$ irradiation measured by detector for mounted sample).

\section{RESULTS AND DISCUSSION}

After identifying a target sequence from $\mathrm{CgA}$ derived peptides to control the synthesis of PDA nanoparticles, some model peptides containing this sequence and some variants therof were tested. The molecular origin of the control exerted by the selected amino acid diad will then be investigated by means of molecular dynalics simulations. Proteins containing or not this diad will then be investigated for their ability to control the self-assembly of PDA, and the structure-properties of those PDA@protein nanoparticles will be investigated in the last section.

3.1. Identification of a Specific Amino Acid Diad Able To Control the Formation of PDA Particles. When dopamine is mixed with different peptides issued from the controlled proteolysis of $\mathrm{CgA}$, its oxidation yields a brownblack solution in all cases. However, in the presence of some peptides issued from the proteolysis of CrgA, the occurrence of huge aggregates issued from the oxidation of the catecholamine is detected by means of visual observation of the solution (Figure 1) whereas for other peptides from the same origin, the suspension remains stable for days. For example, in the presence of bovine chromofungin (Chr, RILSILRHQNLLKELQDLALQGAK) some aggregates including dopamine elute with a large peak (14-18 min) detected at $280 \mathrm{~nm}$ and corresponding to a molecular weight of 120.000 to $70.000 \mathrm{Da}$ (Figure 1A). In contrast, in the presence of bovine catestatin (Cat, RSMRLSFRARGYGFRGPGLQL) the aggregates including dopamine were not detected meaning that they are eluted in the free volume or too large to travel along the size exclusion column (Figure 1A).

In addition, we investigated if the interaction of the 2 antimicrobial peptides Cat and Chr combined with dopamine may modulate their antimicrobial activities against Micrococcus luteus. For Chr that allows for the production of stable PDA suspensions we noted the disappearance of its antibacterial activity (Figure $1 \mathrm{Ba}$ ). In contrast, for Cat (the peptide not able to control the aggregation process) the antimicrobial activity (lytic effect) was maintained (Figure 1Bb). These findings strongly suggest that the active peptides in the control of PDA formation are not available to contact the bacteria, most probably due to their strong interactions with the forming PDA in oxidizing conditions at $\mathrm{pH}=8.5$. There is hence strong evidence that $\mathrm{Chr}$ either looses its activity when PDA 


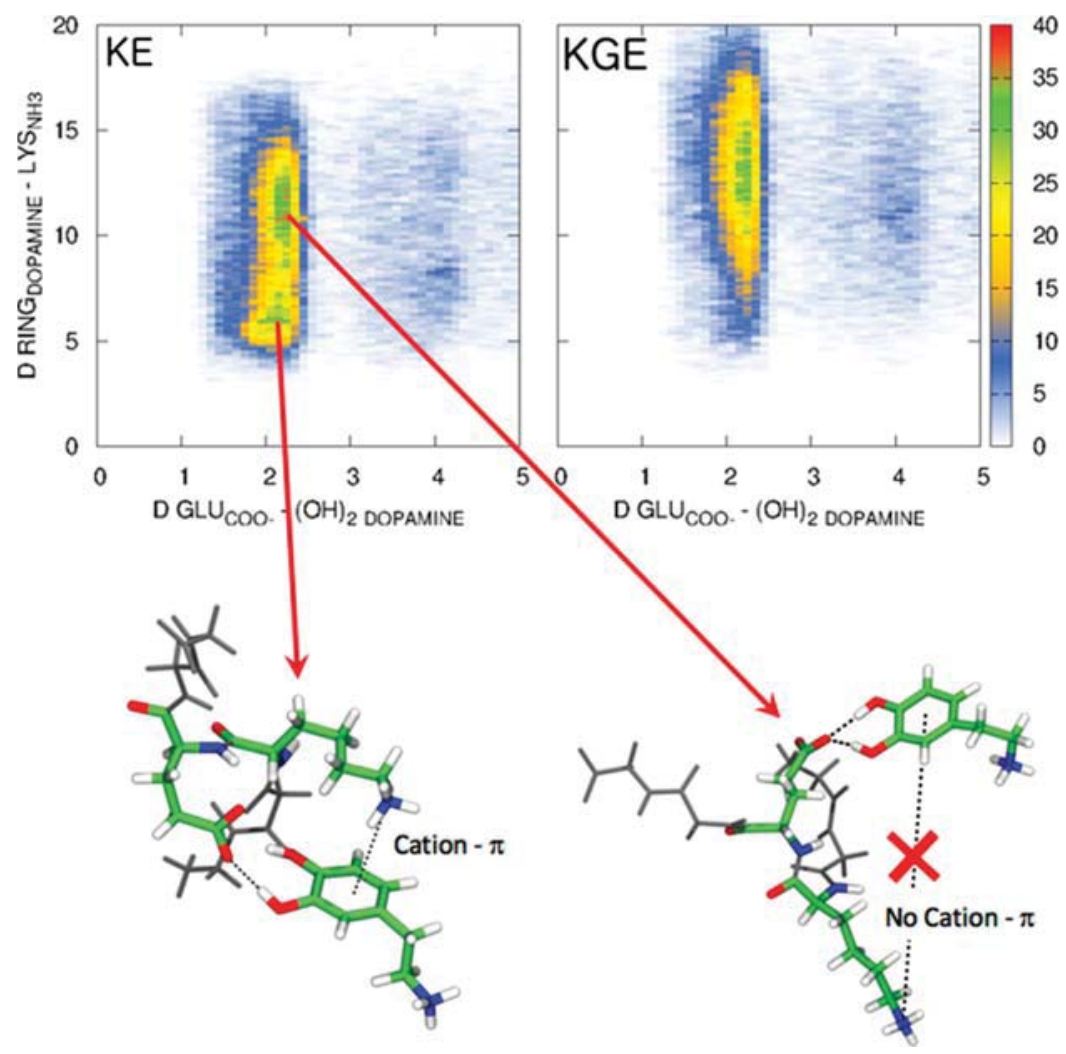

Figure 2. Top: Population analysis in the case of (N-GGKEGG-C (left) and N-GGKGEGG-C (right), as a function of the distance between the center of mass $(\mathrm{CoM})$ of the benzene ring and the $\mathrm{N}$ atom of the $\mathrm{NH}_{3}{ }^{+}$group of the lysine residue and between the $\mathrm{C}_{\text {atom }}$ of the $\mathrm{COO}^{-}$of the glutamic acid (E) residue and the center of mass of both $-\mathrm{OH}$ groups of dopamine. Green regions correspond to populations that are often observed, blue regions correspond to populations that are seldomly observed, and white regions correspond to population that are never observed. Bottom: Typical snapshot of the dopamine -N-GGKEGG-C pair corresponding to the two most observed populations.

formation occurs or more probably that it is bound to PDA particles in a nonactive manner. Indeed proteins are known to bind to quinone groups of PDA via a nucleophilic attack of their amino groups. ${ }^{48,49}$ On the other hand, Cat remains fully active, strongly suggesting that it does not interfere with the formation of PDA.

Additional experiments were then performed with the single model peptides GKEG, GKGEG, and GKGGEG peptides in which the $\mathrm{K}$ and $\mathrm{E}$ amino acids were directly adjacent to each other or separated with one or two glycine residues, with glycine acting as a spacer amino acid. Glycine was chosen as a spacer because of its low steric constraints and because it will not affect the solubility of the peptide in water. By using size exclusion chromatography (SEC) with detection at $214 \mathrm{~nm}$, the peptides GGKEGG, GGKGEGG, and GGKGGEGG were eluted at $26 \mathrm{~min}, 23.5 \mathrm{~min}$, and $19.5 \mathrm{~min}$ respectively (Figure SI1). After incubation with dopamine, only the peptide GGKEGG controls the PDA aggregation with the formation of a complex eluted at $20.5 \mathrm{~min}$. Indeed, it appears that a single glycine residue $(G)$ between $K$ and $E$ was critical for the production of stable PDA suspensions (a low difference in the time of elution $23.5 \mathrm{~min} / 22.5 \mathrm{~min}$ ). This data was validated by the peptide GGKGGEGG including $2 \mathrm{G}$ between $\mathrm{K}$ and $\mathrm{E}$ and the absence of variation in the time of elution for the peptide alone $(19.5 \mathrm{~min})$ and the peptide treated with dopamine (19.5 min). We also tested the single dipeptide KE (dissolved at 1 $\mathrm{mM}$ ) in its ability to control the size of PDA nanoparticles: it plays a role, producing however larger particles, in the 300$500 \mathrm{~nm}$ diameter range, than the GKEG peptide at the same concentration. In this latter case the hydrodynamic diameter of the PDA particles is in the $100-200 \mathrm{~nm}$ range. This means that the positively charged amino and negatively charged carboxyl end groups of the KE containing peptides have to be sufficiently far away from the central $\mathrm{KE}$ diad for allowing an optimized control in the size of PDA (data not shown). It has to be noted also that an equimolar mixture ( $1 \mathrm{mM}$ each) of $\mathrm{K}$ and $\mathrm{E}$ amino acids is inefficient in controlling the size of PDA: in this control experiment a precipitate of PDA was obtained from a $2 \mathrm{mg} \cdot \mathrm{mL}^{-1}$ dopamine solution after $24 \mathrm{~h}$ of oxidation as in the absence of amino acids. This shows that $\mathrm{K}$ and $\mathrm{E}$ have to be covalently bound to exert a templating effect in the assembly of PDA particles.

3.2. Molecular Dynamics. To give some physical insight into the probable role of $\mathrm{KE}$ containing sequences in the control of PDA self-assembly in oxidizing conditions, we performed molecular dynamics (MD) simulations to estimate how dopamine itself interacts with such sequences. We arbitrarily select dopamine as a target molecule and not 5,6dihydroxyindole (DHI) because the latter one undergoes oligomerization whose description would require $a b$ initio MD simulations which are beyond the scope of this study. These simulations are hence only able to describe the first events occurring when dopamine and the target peptides are mixed and totally neglect the subsequent (and fast) oxidation of dopamine.

We will focus on a set of small model peptides of the NGGXGG-C type with $\mathrm{X}=\mathrm{KE}, \mathrm{EK}, \mathrm{KD}$, or KGE (as those issued from the degradation of $\mathrm{ChrA}$ ). All molecular dynamics 
A

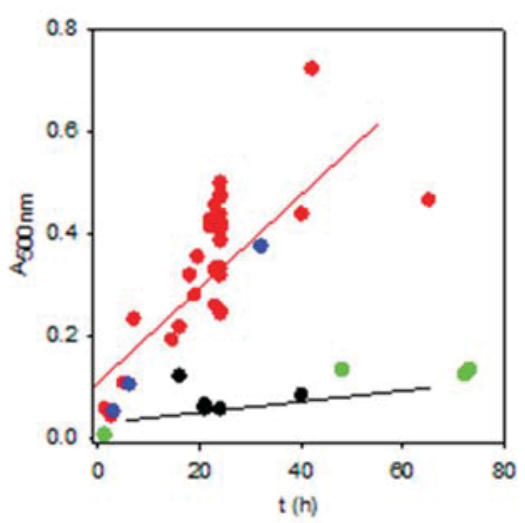

C

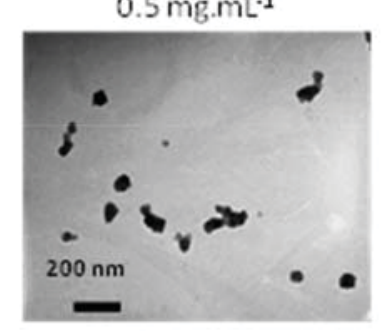

B
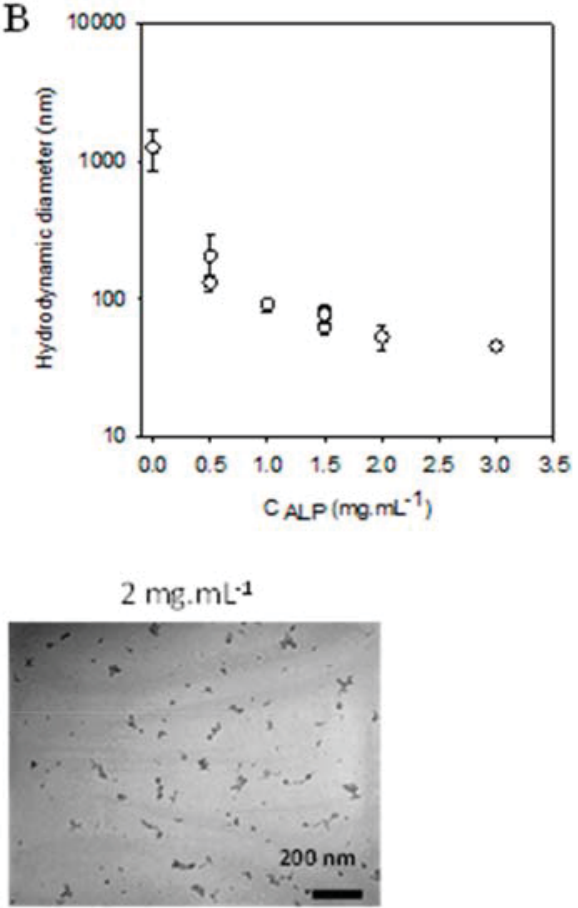

$\mathrm{D}$

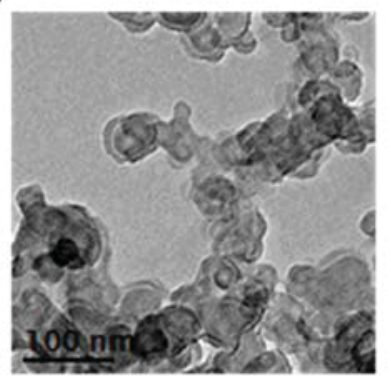

\section{$\mathrm{E}$}

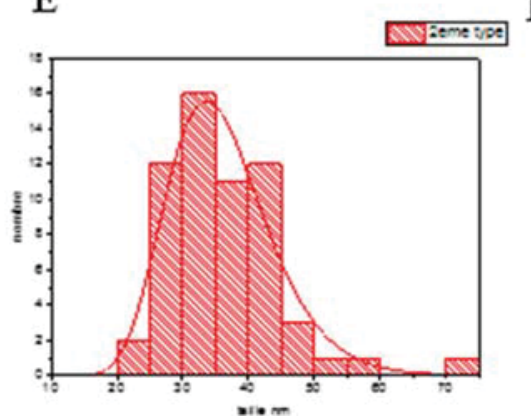

$\mathrm{F}$

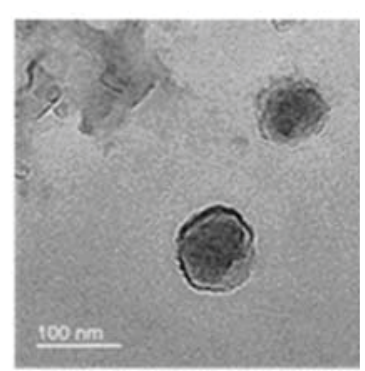

Figure 3. (A) Deposition of PDA on quartz plates monitored at $\lambda=500 \mathrm{~nm}$ as a function of the oxidation time at $\mathrm{pH}=8.5$ : in the absence of Alp (red circles) and in the presence of Alp at 0.1 (green circles) and 0.5 (black circles) $\mathrm{mg} \cdot \mathrm{mL}^{-1}$. Alp was also preadsorbed during $1 \mathrm{~h}$ from a solution at $1 \mathrm{mg} \cdot \mathrm{mL}^{-1}$ before the beginning of dopamine oxidation but in the absence of ALP (blue circles). (B) Evolution of the hydrodynamic radius of PDA particles after $24 \mathrm{~h}$ of oxidation at $\mathrm{pH}=8.5$ in the presence of Alp at different concentrations. The initial dopamine concentration was of 2 $\mathrm{mg} \cdot \mathrm{mL}^{-1}$ in all experiments. (C) Representative TEM micrographs of the PDA@Alp particles obtained after $24 \mathrm{~h}$ of oxidation at $\mathrm{pH}=8.5$ from a 2 $\mathrm{mg} \cdot \mathrm{mL}^{-1}$ dopamine solution in the presence of ALP at 0.5 and $2.0 \mathrm{mg} \cdot \mathrm{mL}^{-1}$. (D) TEM micrograph PDA@Alp particles obtained after $24 \mathrm{~h}$ of oxidation at $\mathrm{pH}=8.5$ from a $2 \mathrm{mg} \cdot \mathrm{mL}^{-1}$ dopamine solution in the presence of Alp at $2.0 \mathrm{mg} \cdot \mathrm{mL}^{-1}$. (E) Size distribution of the PDA@Alp nanoparticles $(n=322)$ obtained after $24 \mathrm{~h}$ of oxidation at $\mathrm{pH}=8.5$ from a $2 \mathrm{mg} \cdot \mathrm{mL}^{-1}$ dopamine solution in the presence of $\mathrm{Alp}$ at $2.0 \mathrm{mg} \cdot \mathrm{mL}^{-1}$. The average size is $(36.1 \pm 4.5) \mathrm{nm}$. (F) High resolution image of an individual PDA@Alp nanoparticle.

simulations started with the dopamine molecule at about $20 \AA$ away from the center of mass of the peptide. During the dynamics we observe that the dopamine molecule is found in close contact with the peptide about $20-30 \%$ of the time. The average time during which this dopamine-peptide pair is formed increases in the order N-GGEKGG-C < N-GGKDGGC < N-GGKGEGG-C < N-GGKEGG-C. (0.131 ns, $0.201 n s$, $0.219 n s$ and $0.246 n s$, respectively). Correspondingly the maximum lifetime during which dopamine interacts with the peptide follows the same trend (7.66 ns, $9.85 n s, 12.81 n s$, and $23.85 n s$, respectively), pointing to the fact that the dopamine molecule interacts the strongest with the N-GGKEGG-C peptide.

A closer look at the specific interactions between the dopamine molecule and the various peptides reveals the hydrogen bond formation between the $-\mathrm{OH}$ or $-\mathrm{NH}_{3}{ }^{+}$ protons of the dopamine molecule with the different carboxylic functions of the peptides situated either on the central E or D residues or on the $\mathrm{C}$-terminus. Hydrogen bonds via the dopamine $-\mathrm{NH}_{3}{ }^{+}$group protons happen however less than $0.5 \%$ of the time and hence will not be discussed any more here.

In the case of the N-GGKEGG-C peptide, the dopamine molecule seems to favor the interaction with the carboxylic group situated on the central glutamic acid (E) residue over the carboxylic group situated on the C-terminus. (10.5\% vs $5.8 \%$ of the time). The reason for the preference of the dopamine molecule interacting with the central glutamate residue certainly comes from the fact that when coordinated to this carboxylic group, the $\mathrm{NH}_{3}{ }^{+}$group of the nearby lysine 
A
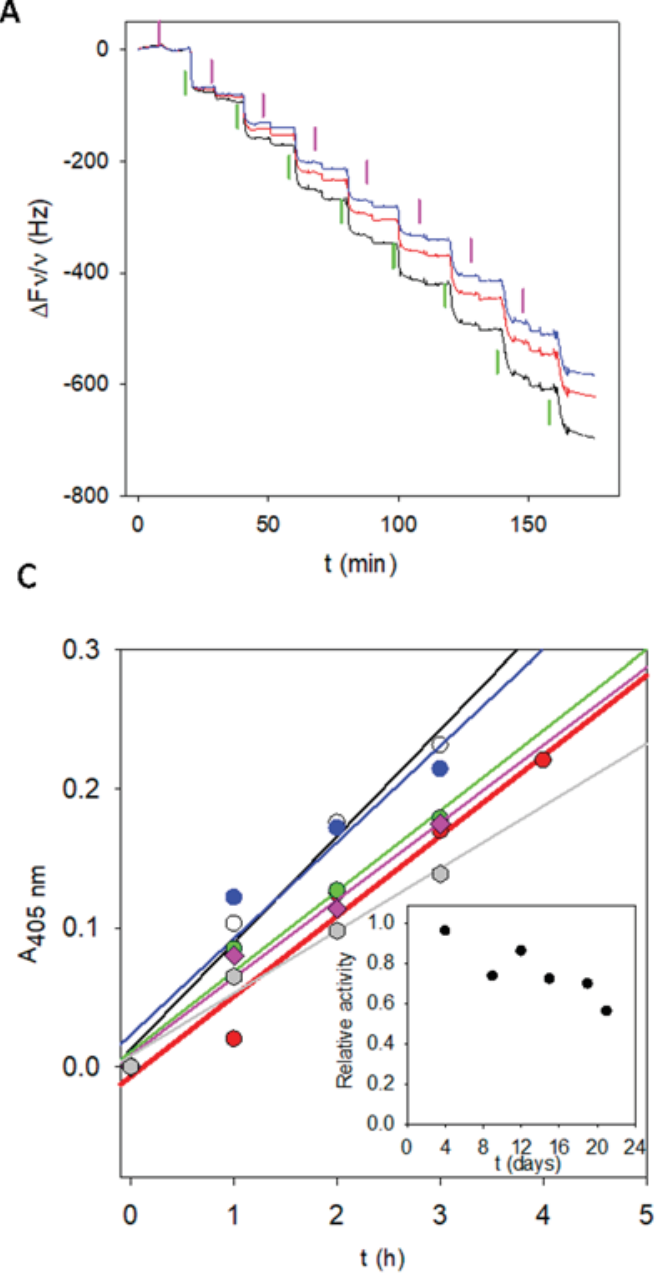

B

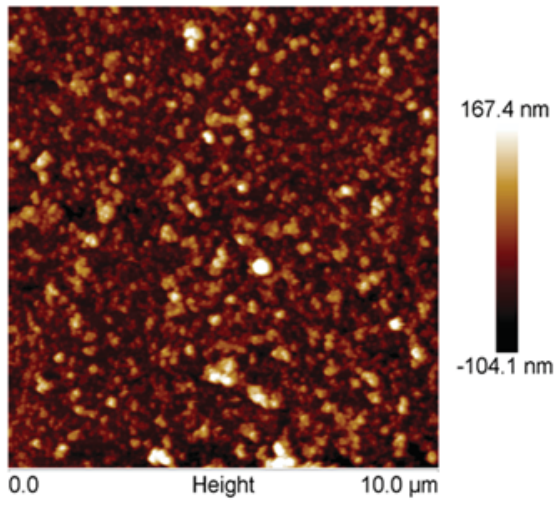

D

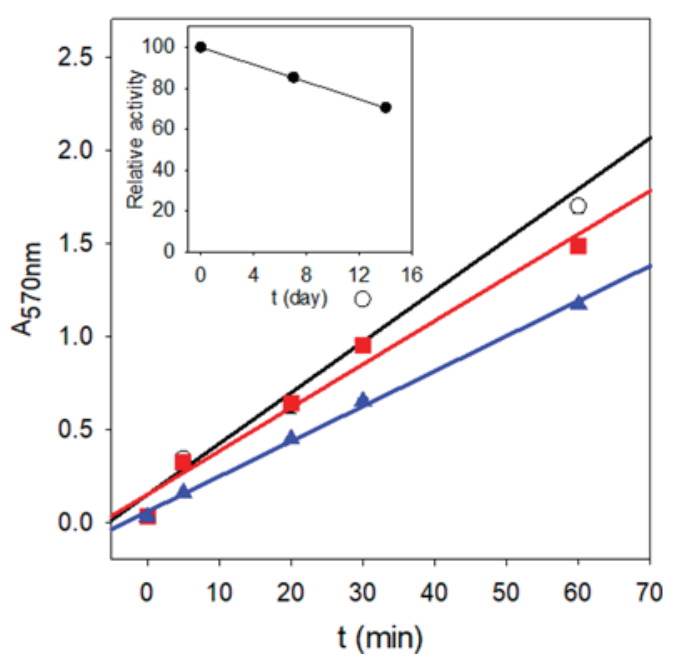

Figure 4. Deposition of PDA nanoparticles capped with enzymes (alkaline phosphatase or a mixture of glucose oxidase and peroxidase) in polyelectrolyte multilayer films and demonstration of long-term conservation of their enzymatic activity. (A) Deposition of PDA@ALP nanoparticles (made in the presence of $1 \mathrm{mg} \cdot \mathrm{mL}^{-1}$ enzyme during $24 \mathrm{~h}$; the excess enzyme is removed by dialysis) with an average diameter of 100 $\mathrm{nm}$ (Figure 3B) in alternation with poly(allylamine hydrochloride) (PAH) to yield a polyelectrolyte multilayer film. The deposition process was followed by means of QCM-D. The green and pink vertical lines correspond to the injection of PDA@Alp and PAH, respectively. (B) Surface morphology of a (PAH-PDA@Alp) $)_{8}$ film obtained by AFM in the dry state and in contact mode. The rms roughness over this $10 \mu \mathrm{m} \times 10 \mu \mathrm{m}$ topography is of $39 \mathrm{~nm}$. (C) Initial hydrolysis rate of paranitrophenolphosphate (PNP) put in contact with a (PAH-PDA@Alp) $)_{8}$ film as a function of the storage time: day 4 (white circles), day 9 (red circles), day 12 (blue circles), day 15 (green circles), day 19 (pink diamonds), and day 21 (gray hexagons). The straight lines correspond to linear regressions to the data. The slope of those lines is divided by the slope obtained immediately after film preparation to yield the relative enzymatic activity (in the inset). (D) Initial rate of oxidation of the peroxidase substrate, gaiacol, measured on a (PAH-PDA@GOX+POX $)_{8}$ polyelectrolyte multilayer film when the film is put in contact with glucose $(1 \mathrm{mM})$ and the peroxidase substrate $(1 \mathrm{mM})$ after different storage times: day 0 (white circles), day 7 (red squares), and day 14 (blue triangles). The straight lines correspond to linear regressions to the data. The slope of those lines is divided by the slope obtained immediately after film preparation to yield the relative enzymatic activity (in the inset).

residue moves toward the benzene ring of the dopamine molecule which then further stabilizes this close contact pair via cation $-\pi$ interactions (Figure 2 ).

One reason for the lack of cation $-\pi$ interactions in the case of the GGKGEGG compared to the GGKEGG system may be due to entropy effects. In fact, adding a $G$ residue between residues $\mathrm{K}$ and $\mathrm{E}$ increases the flexibility of the system and in particular increases the amplitude of the movement between the L-lysine and L-glutamic acid residues. However, to be able to form cation $-\pi$ interactions the $\mathrm{NH}_{3}{ }^{+}$group of the L-lysine residues has to be close to the region where the dopamine molecule docks on to the $\mathrm{COO}^{-}$group of the glutamic acid. This is more likely the case for the less flexible GGKEGG than for the GGKGEGG peptide; hence, the chances of forming cation $-\pi$ interactions are higher in the case of the GGKEGG peptide than for the GGKGEGG peptide

On the other hand in the case of the three remaining peptides (N-GGEKGG-C，N-GGKDGG-C and NGGKGEGG-C) the dopamine is seen to interact more often with the $\mathrm{COO}^{-}$group on the $\mathrm{C}$-terminus than with the one on the central $\mathrm{E}$ or $\mathrm{D}$ residues. (2.8\% vs $7.1 \%, 8.2$ vs $13.5 \%$, and $6.2 \%$ vs $8.4 \%$, respectively.) This shift in tendency stems from various reasons. In the case of the N-GGEKGG-C peptide we observe the formation of hydrogen bonds of the central glutamic acid with the terminal $\mathrm{N}$-terminal $-\mathrm{NH}_{3}$ + group, making it less accessible to the dopamine molecule. In the case of the N-GGKDGG-C peptide the shorter alkyl chain (compared to the $\mathrm{E}$ residue) makes it less flexible and the 
A

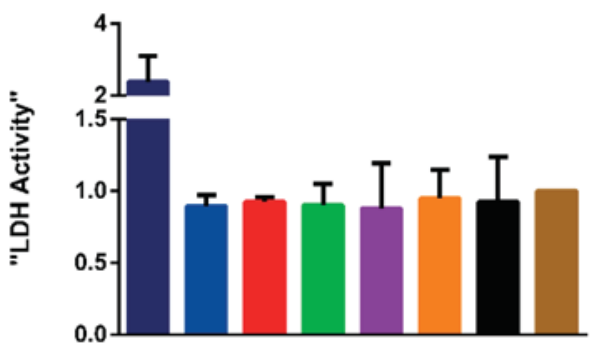

C

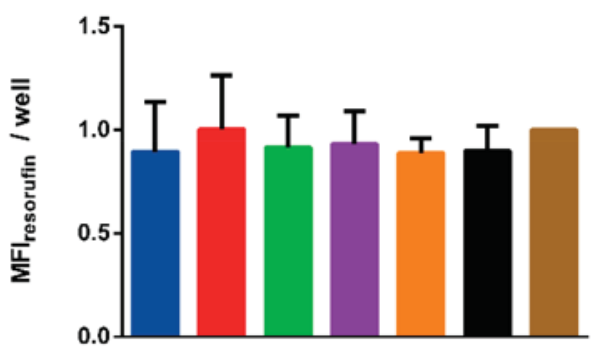

$\mathrm{E}$

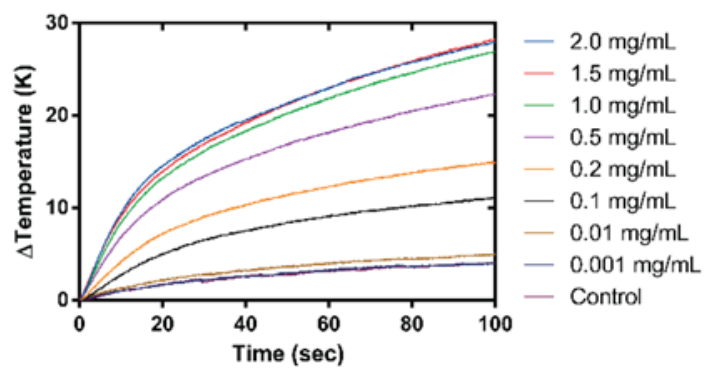

B

D
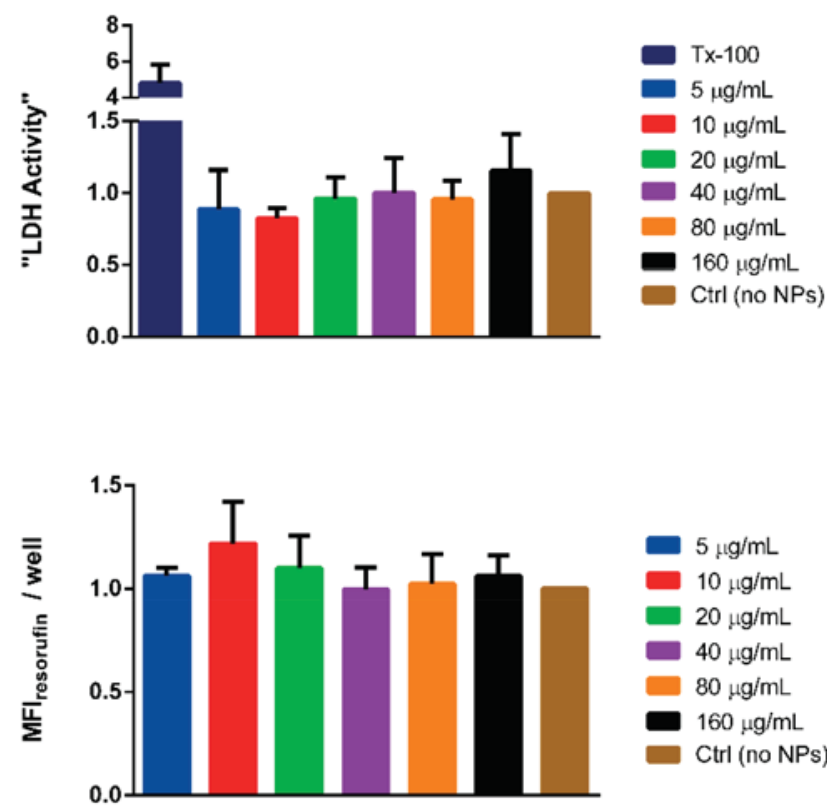

$\mathrm{F}$

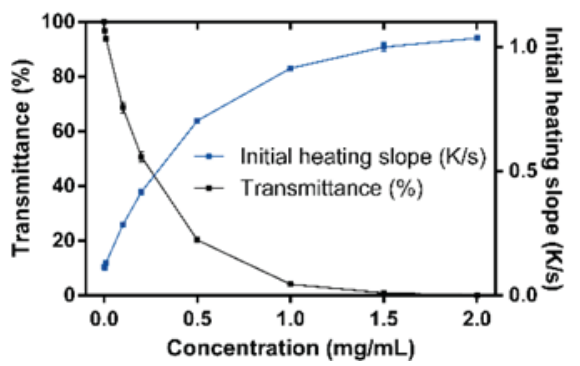

Figure 5. (A, B, C, D) Cytotoxicity evaluation of PDA@HSA nanoparticles in macrophages and human fibroblasts as a function of the PDA@HSA concentration (as indicated on the right) by LDH (A, B) and MTT assay (C, D). The positive control Triton X-100 induced significant cytotoxicity in the LDH assay in both cell types. (E) The PDA@HSA suspension heats up in a concentration-dependent manner as shown by quantification with an IR camera. (F) Temperature increase of PDA@HSA containing solutions right hand scale) and transmittance decrease (left hand scale) upon exposure to UV-light as a function of the concentration in nanoparticles.

$\mathrm{COO}^{-}$group less accessible to the dopamine molecule and hence favors the hydrogen bond with the terminal COOgroup. Finally, in the case of the N-GGKGEGG-C peptide, we no longer observe cation $-\pi$ interactions, and hence interactions with the central group are no longer favored.

In summary we can say that there is a tendency for the dopamine molecule to interact via hydrogen bonding between the $-\mathrm{OH}$ protons of dopamine with the central $\mathrm{E}$ (or D) residue or with the terminal carboxylic group. The former interaction is further stabilized by cation $-\pi$ interaction of the terminal $\mathrm{NH}_{3}{ }^{+}$group of the lysine with the benzene ring of dopamine in the case of the N-GGKEGG-C peptide.

\subsection{Influence of the KE Diad Present in Proteins to} Control the Formation of PDA Particles. These qualitative experimental results and interaction energies-residence times data from MD simulations incited us to investigate a series of proteins to control the aggregation process of PDA, in addition to HSA which has already been shown to allow for a concentration dependent inhibition of PDA deposition on the walls of the reaction beaker and a reduction of the particles hydrodynamic diameter. ${ }^{23}$ It has to be noted that HSA contains $2 \mathrm{KE}$ motifs in its amino acid sequence (see Figure 7 in the Supporting Information).

Among the investigated proteins, two categories emerge:

(i) those which do not influence the PDA deposition on surfaces and its assembly in solution (Hen-egg white lysozyme and $\alpha$-lactalbumine) as shown in Figure 3 and 4 in the Supporting Information.

(ii) and those which simultaneously inhibit film deposition on surfaces and allow for a reduction in particle size after $24 \mathrm{~h}$ of oxidation in the presence of dissolved $\mathrm{O}_{2}$ at $\mathrm{pH}$ 8.5. Among this second category of proteins is human fibrinogen (Figure 5 in the Supporting Information), alkaline phosphatase (Figure 3), and a mixture of glucose oxidase and horseradish peroxidase (Figure 6 in the Supporting Information). A close look at the amino acid sequence of those proteins shows that they all contain the $\mathrm{KE}$ diad of amino acids as the CgA derived peptides (Figure 7 in the Supporting Information). The case of human hemoglobin is surprising: even if it contains the KE diad (Figure 7 in the Supporting Information) exposed to the solvent, this protein does not exert the expected controlled inhibition of PDA 
deposition on the walls of the reaction beaker and the expected reduction in the size of PDA aggregates (Figure 8 in the Supporting Information). However, a closer examination reveals that the $\mathrm{K}$ residue in the unique present $\mathrm{KE}$ diad is postranslationally modified in this protein, making the KE diad sterically unattainable to dopamine. This important result means that the $\mathrm{KE}$ diad has not only to be exposed to the solvent to exert control in the synthesis of PDA but also that the amino acids have to be chemically unmodified.

All our findings are summarized in Table 1:

Table 1. Summary of the Role Played by Diverse Proteins in the Size Control of PDA Particles

\begin{tabular}{|c|c|c|}
\hline Protein & $\begin{array}{l}\text { Number of KE diads } \\
\text { in the protein }\end{array}$ & $\begin{array}{l}\text { Ability to control the } \\
\text { size of the PDA particles }\end{array}$ \\
\hline Human serum albumin & 2 & Yes \\
\hline $\begin{array}{l}\text { Alkaline phosphatase from } \\
\text { porcine mucosa }\end{array}$ & 3 & Yes \\
\hline $\begin{array}{l}\text { Mixture of Glucose } \\
\text { oxidase and peroxidase }\end{array}$ & $1 \mathrm{KE}$ in each protein & yes \\
\hline Bovine fibrinogen & 2 & yes \\
\hline Human Hemoglobin & $\begin{array}{l}1 \text { but } \\
\text { postranslationaly } \\
\text { modified }\end{array}$ & no \\
\hline Hen egg white lysozyme & 0 & no \\
\hline $\begin{array}{l}\text { bovine milk alpha } \\
\text { lactalbumin }\end{array}$ & 0 & no \\
\hline
\end{tabular}

The obtained PDA-Alp composite nanoparticles display a core-shell morphology as shown by cryo-TEM images in the case of PDA@ALP nanoparticles (Figure 3F).

When then coming back to one of our selected biomimetic systems, the eumelanin grains in the skin which are known to be associated with proteins, it comes out that those proteins also contain KE diads. ${ }^{12}$ Based on all these results from the $\mathrm{CgA}$ derived peptides, from $\mathrm{MD}$ simulations, and from globular proteins, we have strong evidence that the KE diad of amino acids interacts specifically with dopamine to control its oxidation and subsequent self-assembly process and that this diad of amino acids may be required to control the selfassembly of PDA from dopamine. At this stage of our research we may however not exclude that other specific sequences of amino acids could control the self-assembly of PDA from dopamine solutions. Note that proteins can conjugate to quinone groups of PDA via nucleophilic groups such as those on L-lysine residues. ${ }^{49}$ But in this investigation, dopamine is added in the protein solution and the proteins are not put in contact with already formed PDA. Hence we believe that the control of PDA size is exerted by the interactions between the $\mathrm{KE}$ diads with dopamine at the beginning of the oxidation process and not via conjugation of the proteins on already formed PDA aggregates. This is our model, but further proofs are required.

The influence of the KE containing peptides and proteins on the size of PDA particles is clearly dependent on the KE/ dopamine ratio mixture (Figure 3B and Figure 5 and 6 in the Supporting Information). Above a critical ratio we assume that most of the dopamine molecules and their oxidation products interact with the introduced peptide/protein and are not available anymore to produce a PDA coating at the surface of the reaction vessel.
3.4. Applications and Biocompatibility of PDA@ protein Nanoparticles. Those protein capped PDA nanoparticles can be coimmobilized with polycations such as poly(allyl amine hydrochloride) to yield polyelectrolyte multilayer films ${ }^{36-38}$ displaying a linear growth with the number of deposition cycles of PDA@protein and PAH (Figure 4A), a smooth morphology (Figure 4B) and stable enzymatic activity upon storage at $4{ }^{\circ} \mathrm{C}$ (Figure $4 \mathrm{C}$ ). Even more interesting, when dopamine is oxidized in the simultaneous presence of glucose oxidase (GOX) and peroxidase (POX), the PDA@GOX+POX nanoparticles (Figure 6 in the Supporting Information) immobilized in polyelectrolyte multilayers can be used as a glucose sensor in the simultaneous presence of glucose and gaiacol (Figure 4D). As for PDA@Alp, the enzymatic activity is very robust upon storage with only $30 \%$ of decrease in the relative enzymatic activity after 14 days of storage (Figure 4D).

Note that PDA nanoparticles containing ALP or GOX+POX display the activity of the used enzyme whereas PDA nanoparticles prepared in the presence of the antimicrobial chromofungin do not display the expected activity. The difference between both situations may come from the difference in size of the used capping agents: the pretty small chromofungin peptide lies probably flat on the surface of the PDA nanoparticles with its antimicrobial sequence not available to the bacteria in contact with the nanoparticles whereas the large enzymes are in contact with the surface of the nanoparticles with only a small fraction of their amino acids, almost nonaffecting their average tertiary structure.

Finally the biocompatibility and heat-induction upon UV light activation of PDA@HSA nanoparticles (synthesized during $24 \mathrm{~h}$ in the presence of $1 \mathrm{mg} \cdot \mathrm{mL}^{-1}$ protein) was tested in order to evaluate their potential for biomedical applications. The particles do not display any measurable cytotoxicity for two cell types tested as mouse monocyte/macrophages (i.e., J774.A1 cell line) and human fibroblasts (i.e., MRC-5 cell line) (Figure 5B). Two different assays have been used, the LDH and the MTT assay, in order to exclude an unspecific interference of one assay with the nanoparticles. In addition, the PDA@HSA nanoparticles are able to convert UV light into heat in a particle concentration dependent manner as expected for a material closely related to eumelanin (Figure 5C). Hence the presence of the proteins does not hinder the photothermal effect already characterized for PDA nanoparticles $(25-43 \mathrm{~nm}$ in diameter) synthesized in reverse microemulsions. ${ }^{50}$

\section{CONCLUSIONS}

Stable polydopamine nanoparticles can be easily synthesized in the presence of proteins containing the KE diad of amino acids in their primary structure. The importance, but probably not the exclusivity, of these two amino acids has been highlighted with small peptides issued from the proteolytic cleavage of CrgA issued from the chromaffin rich vesicles of the surrenal gland as a biomimetic system. In addition small synthetic peptides containing the KE diad allow for a similar control in the oxidation of dopamine and its subsequent self-assembly. Molecular dynamics simulations have provided a molecular explanation for the control exerted by the KE sequence: the hydroxyl groups of the catechol moiety in dopamine form hydrogen bonds with the carboxylic group of glutamate $(\mathrm{E})$ whereas the protonated amino group of the lysine $(\mathrm{K})$ forms a cation $-\pi$ interaction with the aromatic ring of dopamine. These interactions are strongly decreased when a single glycine 
residue is introduced as a spacer between the lysine and glutamate residues.

The importance of the protein-dopamine interactions is manifested by a protein concentration dependent reduction in the size of the obtained core-shell-nanoparticles as well as by a progressive inhibition in the deposition of a polydopamine film on the wall of the reaction beaker. The presence of proteins on the shell of the particles is demonstrated by the enzymatic activity of the obtained nanoparticles in the case of alkaline phosphatase and the glucose oxidase-peroxidase mixture. At this level of our research we cannot exclude that some proteins are also present in the polydopamine rich core of the obtained nanoparticles. Those particles are noncytotoxic up to unusually high concentrations and are able to convert UV light in heat as expected for a polydopamine, eumelanin-like, material. We will exploit the biological potential of the presence of specific proteins in the shell of the particles and the eumelanin photon to heat conversion potential of the core in forthcoming work.

\section{ASSOCIATED CONTENT}

\section{S Supporting Information}

Size exclusion (SEC) chromatograms of the GGKEGG, GGKGEGG and GGKGGEGG peptides and of the same peptides with added dopamine in the presence of Tris buffer $(\mathrm{pH}=8.5)$, schematic representation of the dopamine molecule and the RESP charges used during MD simulation, influence of different proteins (lysozyme, $\alpha$-lactalbumin, human fibrinogen, glucose oxidase + peroxidase and human hemoglobin) on the absorbance at $\lambda=500 \mathrm{~nm}$ of dopamine solutions after $24 \mathrm{~h}$ of oxidation at $\mathrm{pH}=8.5$ and amino acid sequence of the used proteins where the $\mathrm{KE}$ diads are highlighted in red. The Supporting Information is available free of charge on the ACS Publications website at DOI: 10.1021/ acs.biomac. 8 b00818.

(PDF)

\section{AUTHOR INFORMATION}

\section{Corresponding Author}

*E-mail: vball@unistra.fr.

\section{ORCID $\odot$}

Daniel Hauser: 0000-0003-2148-5820

Pierre Schaaf: 0000-0001-7423-5492

Ovidiu Ersen: 0000-0002-1553-0915

Alke Petri-Fink: 0000-0003-3952-7849

Vincent Ball: 0000-0002-7432-4222

\section{Author Contributions}

${ }^{\#}$ C.B. and D.H. contributed equally.

\section{Notes}

The authors declare no competing financial interest.

\section{ACKNOWLEDGMENTS}

This study was supported by the Swiss National Science Foundation through the National Center of Competence in Research Bio-Inspired Materials, the Adolphe Merkle Foundation, and the SNF visitor grant (IZK0Z2_161420/1) for VB. AC thanks the HPC - Center of the Universie de Strasbourg for computing time.

\section{REFERENCES}

(1) Clancy, C. M. R.; Nofsinger, J. B.; Hanks, R. K.; Simon, J. D. A Hierarchical Self-Assembly of Eumelanin. J. Phys. Chem. B 2000, 104, $7871-7873$.

(2) Clancy, C. M. R.; Simon, J. D. Ultrastructural Organization of Eumelanin from Sepia Officinalis Measured by Atomic Force Microscopy. Biochemistry 2001, 40, 13353-13360.

(3) Brenner, M.; Hearing, V. J. The Protective Role of Melanin Against UV Damage in Human Skin. Photochem. Photobiol. 2008, 84, 539-549.

(4) Corani, A.; Huijser, A.; Gustavsson, T.; Markovitsi, D.; Malmqvist, P.Å.; Pezzella, A.; d'Ischia, M.; Sundström, V. Superior Photoprotective Motifs and Mechanisms in Eumelanin Uncovered. J. Am. Chem. Soc. 2014, 136, 11626-11636.

(5) Simon, J. D.; Peles, D. N. The red and the black. Acc. Chem. Res. 2010, 43, 1452-1460.

(6) d'Ischia, M.; Napolitano, A.; Pezzella, A.; Meredith, P.; Sarna, T. Chemical and Structural Diversity in Eumelanins: Unexplored BioOptoelectronic Materials. Angew. Chem., Int. Ed. 2009, 48, 39143921.

(7) Zucca, F. A.; Giaveri, G.; Gallorini, M.; Albertini, A.; Toscani, M.; Pezzoli, G.; Lucius, R.; Wilms, H.; Sulzer, D.; Ito, S.; Wakamatsu, K.; Zecca, L. The Neuromelanin of Human Substantia Nigra: Physiological and Pathogenic Aspects. Pigm. Cell Res. 2004, 17, 610617.

(8) Zecca, L.; Gallorini, M.; Schünemann, V.; Trautwein, A. X.; Gerlach, M.; Riederer, P.; Vezzoni, P.; Tampellini, D. Iron, Neuromelanin and Ferritin Content in the Substantia Nigra of Normal Subjects at Different Ages: Consequences for Iron Storage and Neurodegenerative Processes. J. Neurochem. 2001, 76, 17661773.

(9) Double, K. L. Structural Characteristics of Human Substantia Nigra Neuromelanin and Synthetic Dopamine Melanins. J. Neurochem. 2000, 75, 2583-2589.

(10) Ito, S.; Wakamatsu, K. Chemistry of Mixed MelanogenesisPivotal Role of Dopaquinone. Photochem. Photobiol. 2008, 84, 582592.

(11) d'Ischia, M.; Wakamatsu, K.; Napolitano, A.; Briganti, S.; Garcia-Borron, J.-C.; Kovacs, D.; Meredith, P.; Pezzella, A.; Picardo, M.; Sarna, T.; Simon, J. D.; Ito, S. Melanins and Melanogenesis: Methods, Standards, Protocols. Pigm. Cell Melanoma Res. 2013, 26, 616-633.

(12) Kushimoto, T.; Basrur, V.; Valencia, J.; Matsunaga, J.; Vieira, W. D.; Ferrans, V. J.; Muller, J.; Appella, E.; Hearing, V. J. A Model for Melanosome Biogenesis Based on the Purification and Analysis of Early Melanonosomes. Proc. Natl. Acad. Sci. U. S. A. 2001, 98, 1069810703.

(13) Bridelli, M. G. Self-Assembly of Melanin Studied by Laser Light Scattering. Biophys. Chem. 1998, 73, 227-239.

(14) Ju, K.-Y.; Lee, Y.; Lee, S.; Park, S. B.; Lee, J.-K. Bioinspired Polymerization of Dopamine to Generate Melanin-like Nanoparticles Having an excellent free-radical Scavenging Property. Biomacromolecules 2011, 12, 625-632.

(15) Wang, Z.; Wang, K.; Zhang, Y.; Jiang, Y.; Lu, X.; Fang, L.; Gan, D.; Lv, C.; Zhang, H.; Qu, S. Protein-Affintive Polydopamine Nanoparticles as an Efficient Surface Modification Strategy for Versatile Porous Scaffolds Enhancing Tissue Regeneration. Particles \& Part. Syst. Charac 2016, 33, 89-100.

(16) Han, L.; Zhang, Y.; Lu, X.; Wang, K.; Wang, Z.; Zhang, H. Polydopamine Nanoparticles Modulating Stimuli Responsive PNIPAM Hydrogels with Cell/Tissue Adhesiveness. ACS Appl. Mater. Interfaces 2016, 8, 29088-29100.

(17) Micillo, R.; Panzella, L.; Koike, K.; Monfrecola, G.; Napolitano, A.; d'Ischia, M. "Fifty Shades" of Black and Red or How Carboxyl Groups Fine Tune Eumelanin and Pheomelanin Properties. Int. J. Mol. Sci. 2016, 17, 746

(18) Strube, O. I.; Büngeler, A.; Bremser, W. Site-Specific in Situ Synthesis of Eumelanin Nanoparticles by an Enzymatic Autodeposition-like process. Biomacromolecules 2015, 16, 1608-1613. 
(19) Büngeler, A.; Hämisch, B.; Huber, K.; Bremser, W.; Strube, O. I. Insight Into the Final Step of the Supramolecular Buildup of Eumelanin. Langmuir 2017, 33, 6895-6901.

(20) Arzillo, M.; Mangiapia, G.; Pezzella, A.; Heenan, R. K.; Radulescu, A.; Paduano, L.; d'Ischia, M. Eumelanin Buildup on the Nanoscale: Aggregate Growth/Assembly and Visible Absorption Development in Biomimetic 5,6-dihydroxyindole Polymerization. Biomacromolecules 2012, 13, 2379-2390.

(21) Ponzio, F.; Bertani, Ph.; Ball, V. Role of Surfactants in the Control of Dopamine-Eumelanin Particle Size and in the Inhibition of Film Deposition at Solid-Liquid Interfaces. J. Colloid Interface Sci. 2014, 431, 176-179.

(22) Lampel, A.; McPhee, S. A.; Park, K.-A.; Scott, G. G.; Humagain, S.; Hekstra, D. R.; Yoo, B.; Frederix, P. W. J. M.; Li, T.-D.; Abzalimov, R. R.; Greenbaum, S. G.; Tuttle, T.; Hu, C.; Bettinger, C. J.; Ulijn, R. V. Polymeric Peptide Pigments with sequence-encoded properties. Science 2017, 356, 1064-1068.

(23) Chassepot, A.; Ball, V. Human Serum Albumin and Other Proteins as Templating Agents for the Synthesis of Nanosized Dopamine-Eumelanin. J. Colloid Interface Sci. 2014, 414, 97-102.

(24) Della Vecchia, F.; Cerruti, P.; Gentile, G.; Errico, M. E.; Ambrogi, V.; D’Errico, G.; Longobardi, S.; Napolitano, A.; Paduano, L.; Carfagna, C.; d'Ischia, M. Artificial Biomelanin: Highly Light Absorbing Nano-Sized Eumelanin by Biomimetic Synthesis in Chicken Egg White. Biomacromolecules 2014, 15, 3811-3816.

(25) Xiao, M.; Li, Y.; Allen, M. C.; Deheyn, D. D.; Yue, X.; Zhao, J.; Gianneschi, N. C.; Shawkey, M. D.; Dhinojwala, A. Bio-Inspired Structural Colours Produced via Self-Assembly of Synthetic Melanin Nanoparticles. ACS Nano 2015, 9, 5454-5460.

(26) McGinness, J.; Corry, P.; Proctor, P. Amorphous Semi conductor Switching in Melanins. Science 1974, 183, 853-855.

(27) Bothma, J. P.; de Boor, J.; Divakar, U.; Schwenn, P. E.; Meredith, P. Device-Quality Electrically Conducting Melanin Thin Films. Adv. Mater. 2008, 20, 3539-3542.

(28) Lee, H.; Dellatore, S. M.; Miller, W. M.; Messersmith, P. B. Mussel-Inspired Surface Chemistry for Multifunctional Coatings. Science 2007, 318, 426-430.

(29) Kang, S. M.; Rho, J.; Choi, I. S.; Messersmith, P. B.; Lee, H. Norepinephrine: Material-Independent, Multifunctional Surface Modification Reagent. J. Am. Chem. Soc. 2009, 131, 13224-13225.

(30) Liu, Y.; Ai, K.; Lu, L. Polydopamine and its Derivative Materials: Synthesis and Promising Applications in Energy, Environmental, and Biomedical Fields. Chem. Rev. 2014, 114, 5057-5115.

(31) Lee, B. P.; Messersmith, P. B.; Israelachvili, J. N.; Waite, J. H. Mussel-Inspired Adhesives and Coatings. Annu. Rev. Mater. Res. 2011, $41,99-132$.

(32) Crivellato, E.; Nico, B.; Ribatti, D. The Chromaffin Vesicle: Advances in Understanding the Composition of a Versatile, Multifunctional Secretary Organelle. Anat. Rec. 2008, 291, 15871602.

(33) Aslam, R.; Atindehou, M.; Lavaux, T.; Haïkel, Y.; Schneider, F.; Metz-Boutigue, M.-H. Chromogranin A-Derived Peptides are Involved in Innate Immunity. Curr. Med. Chem. 2012, 19, 41154123.

(34) Dominguez, N.; Estevez-Herrera, J.; Borges, R.; Machado, J. D. The Interaction Between Chromogranin $\mathrm{A}$ and Catecholamines Governs Exocytosis. FASEB J. 2014, 28, 4657-4667.

(35) Ogata, T. Ogata A Über die Henlesche Chromreaktion der Sogennaten Chromaffinen Zellen und den Mikroskopischen Nachweis des Adrenalins. Ziegler Beitr 1923, 71, 376-387.

(36) Decher, G. Fuzzy nanoassemblies: Toward Layered Polymeric Multicomposites. Science 1997, 277, 1232-1237.

(37) Ariga, K.; Hill, J. P.; Ji, Q. Layer-by-layer Assembly as a Versatile Bottom-up Nanofabrication Technique for Exploratory Research and Realistic Applications. Phys. Chem. Chem. Phys. 2007, 9, 2319-2340.

(38) Richardson, J. J.; Cui, J. W.; Bjornmalm, M.; Braunger, J. A.; Ejima, H.; Caruso, F. Innovation in Layer-by-layer Assembly. Chem. Rev. 2016, 116, 14828-14867.
(39) Aslam, R.; Marban, C.; Corazzol, C.; Jehl, F.; Delalande, F.; Van Dorsselaer, A.; Prevost, G.; Haikel, Y.; Taddei, C.; Schneider, F.; Metz-Boutigue, M.-H.. Cateslytin, a chromogranin A derived peptide is active against Staphylococcus aureus and resistant to degradation by its proteases. PLoS One 2013, 24, e68993

(40) Bulet, P.; Dimarcq, J.-L.; Hetru, C.; Lagueux, M.; Charlet, M.; Hegy, G.; Van Dorsselaer, A.; Hoffmann, J. A Novel Inducible Antibacterial Peptide of Drosophila Carries an o-Glycosilated Substitution. J. Biol. Chem. 1993, 268, 14893-14897.

(41) Pearlman, D. A.; Case, D. A.; Caldwell, J. W.; Ross, W. S.; Cheatham, T. E., III; DeBolt, S.; Ferguson, D.; Seibel, G.; Kollman, P. AMBER, a Package of Computer Programs for Applying Molecular Mechanics, Normal Mode Analysis, Molecular Dynamics and Free Energy Calculations to Simulate the Structural and Energetic Properties of Molecules. Comput. Phys. Commun. 1995, 91, 1-41.

(42) Maier, J. A.; Martinez, C.; Kasavajhala, K.; Wickstrom, L.; Hauser, K. E.; Simmerling, C. ff14SB: Improving the Accuracy of Protein Side Chain and Backbone Parameters from ff99SB. J. Chem. Theory Comput. 2015, 11, 3696-3713.

(43) Bayly, C. I.; Cieplak, P.; Cornell, W.; Kollman, P. A WellBehaved Electrostatic Potential Based Method Using Charge Restraints for Deriving Atomic Charges: the RESP Model. J. Phys. Chem. 1993, 97, 10269-10280.

(44) Frisch, M. J., Trucks, G. W., Schlegel, H. B., Scuseria, G. E., Robb, M. A., Cheeseman, J. R., Scalmani, G., Barone, V., Mennucci, B., Petersson, G. A., Nakatsuji, H., Caricato, M., Li, X.; Hratchian, H. P., Izmaylov, A. F., Bloino, J.; Zheng, G., Sonnenberg, J. L., Hada, M., Ehara, M., Toyota, K., Fukuda, R., Hasegawa, J., Ishida, M., Nakajima, T., Honda, Y., Kitao, O., Nakai, H., Vreven, T., Montgomery, J. A., Jr., Peralta, J. E., Ogliaro, F., Bearpark, M., Heyd, J. J., Brothers, E., Kudin, K. N., Staroverov, V. N., Kobayashi, R.; Normand, J., Raghavachari, K., Rendell, A., Burant, J. C., Iyengar, S. S., Tomasi, J., Cossi, M.; Rega, N., Millam, J. M., Klene, M., Knox, J. E., Cross, J. B., Bakken, V., Adamo, C., Jaramillo, J., Gomperts, R., Stratmann, R. E., Yazyev, O., Austin, A. J., Cammi, R., Pomelli, C., Ochterski, J. W., Martin, R. L., Morokuma, K., Zakrzewski, V. G., Voth, G. A., Salvador, P., Dannenberg, J. J., Dapprich, S., Daniels, A. D., Farkas, Ö., Foresman, J. B., Ortiz, J. V., Cioslowski, J., Fox, D. J.Gaussian 09, Revision E.01; Gaussian, Inc.: Wallingford, CT, 2009.

(45) Roe, D. R.; Cheatham, T. E., III PTRAJ and CPPTRAJ: Software for Processing and Analysis of Molecular Dynamics Trajectory Data. J. Chem. Theory Comput. 2013, 9, 3084-3095.

(46) Humphrey, W.; Dalke, A.; Schulten, K. VMD - Visual Molecular Dynamics. J. Mol. Graphics 1996, 14, 33-38.

(47) Bernsmann, F.; Ponche, A.; Ringwald, C.; Hemmerlé, J.; Raya, J.; Bechinger, B.; Voegel, J.-C.; Schaaf, P.; Ball, V. Characterization of Dopamine-Melanin Growth on Silicon Oxide. J. Phys. Chem. C 2009, $113,8234-8242$.

(48) Meredith, P.; Sarna, T. The Physical and Chemical Properties of Eumelanin. Pigm. Cell Res. 2006, 19, 572-594.

(49) Lee, H.; Rho, J.; Messersmith, P. B. Facile Conjugation of Biomolecules onto Surfaces via Mussel Adhesive Protein Inspired Coatings. Adv. Mater. 2009, 21, 431-436.

(50) Liu, F.; He, X.; Zhang, J.; Chen, H.; Zhang, H.; Wang, Z. Controllable Synthesis of Polydopamine Nanoparticles in Microemulsions with $\mathrm{pH}$ Activable Properties for Cancer Detection and Treatment. J. Mater. Chem. B 2015, 3, 6731-6739. 